\title{
Editorial
}

\section{A Memorable Farewell to Case Reports}

\section{Un memorable adiós a los informes de casos}

\author{
Nicolas Fernandez $z^{1,2,3,4}$ \\ ${ }^{1}$ Editorial Committee of, Urologia Colombiana, , Bogota, Colombia \\ 2 Division of Urology, Hospital Universitario San Ignacio, Pontificia \\ Universidad Javeriana, Bogota, Colombia \\ ${ }^{3}$ Department of Urology, Fundación Santa Fe de Bogotá, Bogota, \\ Colombia \\ ${ }^{4}$ Division of Urology, Hospital for SickKids, University of Toronto, \\ Toronto, ON, Canada
}

Urol Colomb 2019;28:1-2.

McMaster University in Hamilton, Canada, is the birthplace of evidence-based medicine (EBM), in the 1990s. Since its inception, nearly universal implementation of EBM has helped to guide the progress of medicine. Prior to the era of EBM, the art of practicing medicine was largely influenced by expert opinion and an authoritative approach to teaching medicine and promoting academic inquiry. With the birth of EBM, however, research standards have become higher, and, thus, academic expectations have become more rigorous and more complex. This new EBM revolution of having scientific and evidence-based support to make clinical decisions has drastically shifted gears for the practice of medicine. Nowadays, advancements in oncology, internal medicine, pediatrics, and urology, are universally supported by the highest levels of evidence. Implementation of novel treatments are changing paradigms, and these would never have happened if medical evolution had not been supported by EBM.

Along with the birth of EBM, another critical event occurred; the birth of the internet. The eruption of the internet led to the introduction of electronic versions of journals and almost immediate access to the latest breaking literature. The subsequent emergence of open access journals also led to increased consumption of academic literature. Editors faced a complex process of manuscript selection to choose only the highest quality literature from endless volumes of publications. As a result of the momentum of EBM, highly respected journals are now expected to publish manuscripts with the highest levels of evidence and have been pressured into rejecting one of the most ancient forms of scientific articles, the case report.

Address for correspondence Nicolas Fernandez, MD, PhD, Division of Urology, Hospital Universitario San Ignacio,

Pontificia Universidad Javeriana, Bogota, Colombia

(e-mail: Fernandez.j@javeriana. edu.co).
The case report is at the foundation of almost every clinician's curriculum vitae, as this is almost unanimously the way clinicians start their literary careers. Young, knowledge-hungry medical students are eager and inspired by the magic of rare medical conditions worthy of case reports, which offer these students the opportunity of being the lucky one to identified and publish on a rare condition. It is interesting to note that some medical innovations, such as minimally invasive laparoscopic and robotic-assisted surgery, largely owe their successful adoption to case reports and case series. However, there is not a very rigorous scientific process underlying the case report. It is mainly for this reason that the highly competitive publication industry now rarely offers opportunities to publish case reports, as scientific journals are pressured to maintain highquality EBM standards. Thus, to achieve competitive impact factors, case reports are becoming a thing of the past.

As junior scientists trying to motivate young generations to pursue academic medicine, this decision to remove case reports is bittersweet. We have never seen a better, more effective way to positively impact and inspire an aspiring academician than to publish early on in the medical career. Complex, longitudinal projects, which may not be completed by the time a rotation ends, are of questionable benefit and impact. The process of generating a question, developing hypotheses and scientific methods, and publishing the conclusions yielded from that process, however, may be one of the most powerful ways to have a profound impact on one's aspirations of becoming a scientist. What better way to achieve all of these goals in a feasible timeline than with a case report?

Regardless of our personal stance on the importance of case reports, we acknowledge that the world of scientific and

Copyright $\odot$ 2019, Sociedad Colombiana License terms de Urología. Publicado por Thieme Revinter Publicações Ltda., Rio de Janeiro, Brazil. Todos los derechos reservados.

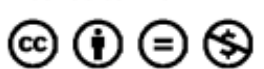

DOI https://doi.org/

ISSN 0120-789X.

eISSN 2027-0119. 
academic literature is demanding higher and higher standards. If we do not adapt, we will become obsolete. We appreciate the challenges that come with evolution, and this new step is one of them.

As we raise academic standards by eliminating the case report, however, we must also seek to ensure there are still literary avenues for inspiring new ideas and new generations. Without creative yet thoughtful adaptation, we might stunt certain areas of scientific inquiry, such as genetics and technology, that often depend on case reports for their scientific voice. Maybe a unique online forum, an independent journal, or letters to the editor should be developed for circulation of these innovative ideas. The possibilities are endless but must still take into consideration the need to respect a high scholarly standard.
This edition will be a historic moment for Urologia Colombiana as we take a step forward in its evolution. As one of the most important urological publications of our country, and as one of the fastest growing journals in the continent, it is the responsibility of Urologia Colombiana to position itself as one of the most recognized journals. It is, thus, our responsibility to move onward and pay tribute to the case report before biding it adieu. We thank all the authors who dedicated their time and inspiration toward publishing their case reports, and we invite you all to join us in this new era.

We would like to acknowledge Dr. Jessica Hannick, MD, MSc. Division of Urology, McMaster Children's Hospital and McMaster University, Hamilton, ON, for actively helping with the edition of this editorial. 